http://jmscr.igmpublication.org/home/ ISSN (e)-2347-176x ISSN (p) 2455-0450

crossref DOI: https://dx.doi.org/10.18535/jmscr/v8i6.91

\author{
Journal Of Medical Science And Clinical Research \\ IGM Publication \\ An official Publication of IGM Publication
}

\title{
Cognitive Impairment in Geriatric Patients with Hip Fractures
}

\author{
Authors \\ Dr Ramanujam $\mathbf{P}^{1}$, Dr Sabarisree $\mathbf{M}^{2^{*}}$ \\ ${ }^{1}$ Associate Professor, in Orthopaedics, Government Medical College, Trivandrum \\ ${ }^{2}$ Additional Professor in Orthopaedics, Government Medical College, Trivandrum \\ *Corresponding Author \\ Dr Sabarisree M
}

\begin{abstract}
Background: Geriatric population includes patients above 65 (sixty five years). They are susceptible to fractures around Hip joint. It can be intracapsular, intertrochantericor subtrochanteric patients. They have various co-morbidities and surgical outcome largely depends on their cognitive status even if the orthopaedic surgical fixation and medical management is excellent.

This study aims at assessing the cognitive function of patients above 65 years on the basis of a minimental state score questionnaire.

If the score is on the lower side the relatives and care givers are warned of a less favourable outcome even if surgery is done.

Materials and Methods: This is a prospective study of 60 (sixty) patients; both male and female admitted in Government Medical College, Trivandrum from 2019-20 (May). All patients had varying types of Hip fractures, they also had comorbidities like diabetes mellitus, hypertension, CVA. The focus was on cognitive function traced on Minimental state questionnaire. It includes vertbal, as well as writing and reading components. A total sense of 30 points is the maximum. Patients having sure of 27-30 were considered normal with no significant dementia.

A score of 23-27 was considered borderline score below 23 had significant cognitive disturbance.

Results: Forty four (44) patients above the age of 65 (sixty five) had significant cognitive impairment according to this scale, 21 had scores below 23 out of 30. However they were in the age group of 85 and above.

Hence assessment of mental state is a good guide to predict the functional outcome of the planned orthopedic surgery.

Conclusion: Dementia or rather cognitive disturbances are common in elderly. Awareness of this fact is equally important for the surgeon who makes the decision to operate and also to inform the care givers.

Operating on a demented patient will be a surgical exercise and a burden for the relatives.
\end{abstract}

\section{Introduction}

Patients above 65 years tend to have age related memory loss. This can be associated with other comorbid conditions like diabetes, cerebrovascular accidents, parkinsonism.
Alzheimers dementia is also a major cause. As the percentage of elderly population is on the increase, these diseases are inevitable. Coupled with osteoporosis the elderly are susceptible to fractures around Hip. Surgical stabilizations like 
dynamic Hip screw, proximal femoral nail, Hemi or Bipolar arthroplasties are the commonly done surgeries. Poor bone stock compromises results of surgery. Altered Mental state further compromises the results. Hence this study is to quickly assess the mental state before deciding upon the line of management.

\section{Objectives}

1. To assess the cognitive state of patients admitted with Hip fractures above 65 years. Based on mini mental state questionnaire given in vernacular language.

2. To decide whether surgery will be useful based on the scores obtained.

If there is a poor or border line score the relatives are warned of a poor result and advised a conservative option.

\section{Inclusion Criteria}

1. All patients male and female sustaining Hip fractures above 65 years.

2. Bed ridden patients who had fractures.

3. Patients with CVA, Alzheimers and other neurologic illness on treatment.

\section{Exclusion Criteria}

1. Patients below 65 years having Hip fractures.

2. Patients with psychiatric illness on treatment.

3. Elderly patients with pathologic fractures.

\section{Results}

44 patients were found to have score less than 26 indicating significant cognitive disturbance $72 \%$ in the elderly.

23 patients had scores between 23-26 (38\%) showing a border line cognitive impairment.

21 patients had score below 23 which (32\%) indicates significant impairment.

34 patients were above 80 years of age.
In our study 45 (74\%) patients were females. 48 (80\%) patients had other co-morbid factors like CVA, DM, Hypertension.

Trivial fall was the cause of trauma in 55 patients (95\%)

\section{Summary of Results}

\section{Minimental State Score}

\begin{tabular}{|l|l|}
\hline $27-30$ & 16 \\
\hline $23-26$ & 23 \\
\hline Below 23 & 21 \\
\hline
\end{tabular}

\section{Gender Distribution}

\begin{tabular}{|l|l|}
\hline MALE & 15 \\
\hline FEMALE & 45 \\
\hline
\end{tabular}

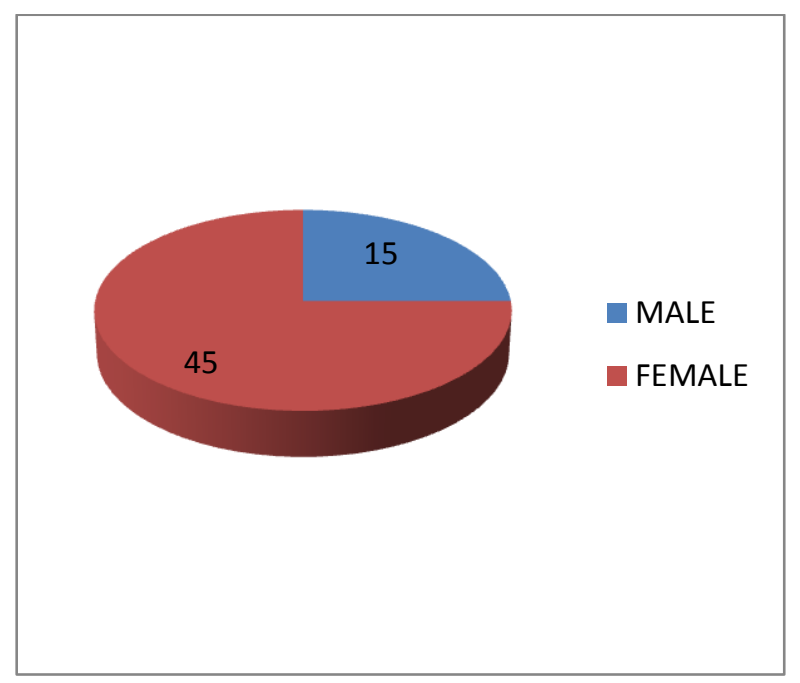

\section{Age Distribution}

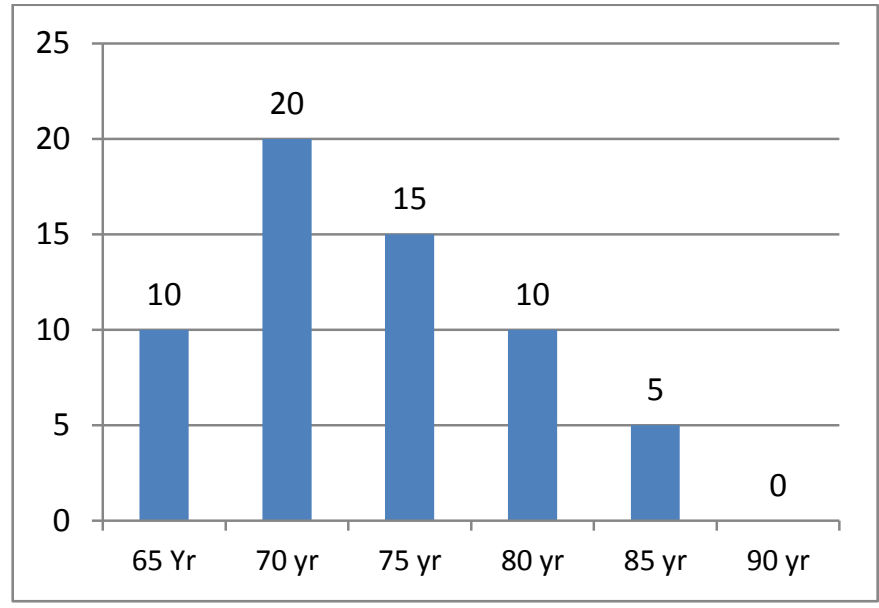


Correlation between Mental State and Age

\begin{tabular}{|l|c|}
\hline Age in years & No \\
\hline $65-70$ & 8 \\
\hline $70-75$ & 4 \\
\hline $75-80$ & 3 \\
\hline $80-85$ & 1 \\
\hline $85-90$ & 0 \\
\hline Total & 16 \\
\hline
\end{tabular}

\section{3 - 26 Borderline Score}

\begin{tabular}{|l|c|}
\hline Age in years & No \\
\hline $65-70$ & 2 \\
\hline $70-75$ & 4 \\
\hline $75-80$ & 4 \\
\hline $80-85$ & 6 \\
\hline $85-90$ & 7 \\
\hline Total & 23 \\
\hline
\end{tabular}

\section{3 and Below-Severe}

\begin{tabular}{|l|c|}
\hline Age in years & No \\
\hline $65-70$ & 1 \\
\hline $70-75$ & 1 \\
\hline $75-80$ & 3 \\
\hline $80-85$ & 8 \\
\hline $85-90$ & 8 \\
\hline Total & 21 \\
\hline
\end{tabular}

Males Vs Females with score 23 below

\begin{tabular}{|l|c|}
\hline MALE & 5 \\
\hline FEMALE & 16 \\
\hline
\end{tabular}

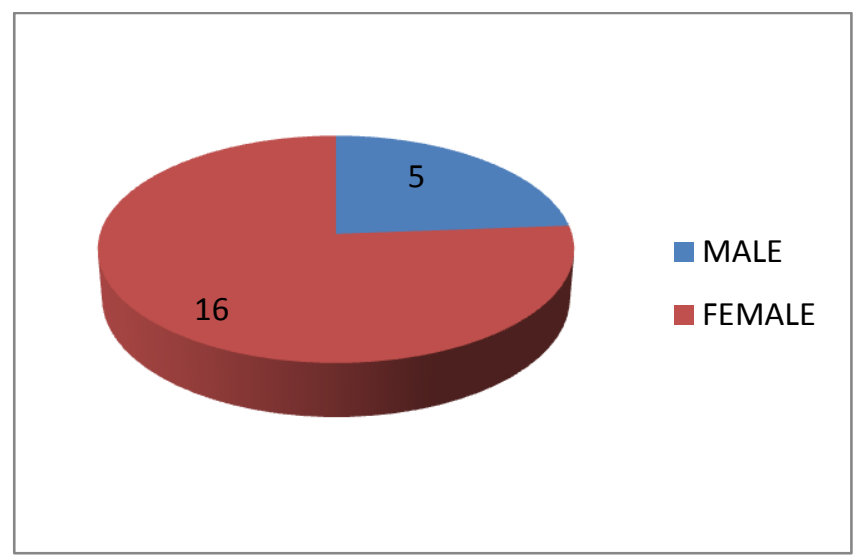

\section{Discussion}

The age group above 80 and especially those above 85 years had significant cognitive impairment in our study.

The relatively younger geriatric age group fared well. The incidence of dementia was much less in the 65-70 age groups.
Females constituted more in the older age groups indicating more life expectancy and the incidence of dementia was higher in older age groups.

Female patients in the age group of 80 and above were the most affected.

Hence as the age advances the risk of fracture and coexisting cognitive impairment increases proportionately.

This has a bearing on surgical decision making.

\section{Conclusion}

Minimental state assessment is a quick and easily done test on geriatric patients. It helps to roughly assess the cognitive status. It cannot be compared with detailed evaluation done by neurologic or psychiatrists however the surgeon can identify the risk factor and advise the relatives of outcome of the prepared surgery.

Option of conservative treatment can also be considered in the very elderly.

\section{References}

1. Given JL, Marcantonio ER, Functional recovery after Hip Fracture Combined effect of depressive symptoms cognitive impairment.2008 Pubmed.

2. Mussolino. ME Depression and Hip Fractures epidemiologic follow up. 2005 Pubmed

3. Liponski2.J Delirium in the elderly patients with Hip fractures. New England Journal of Medicine 1989.

4. Mossey J.M. Knot. K Effects of persistent depressive symptoms on Hip fracture recovery. Journal of Gerontology 1990.

5. Hamilton. M. Development of a rating scale for primary depression illness in patients with Hip fractures-British Journal of Clinical Psychology-1967.

6. Lenze E.J. Skidmore E Rabsence of depression in elderly person after Hip fractures -American Journal of Geriatrics 2007. 